\title{
Comparing Comprehensiveness in Primary Care Specialties and Their Effects on Healthcare Costs and Hospitalizations in Medicare Beneficiaries
}

\author{
Tracey L. Henry, MD MPH MS ${ }^{7}$, Stephen Petterson, PhD², Russell S. Phillips, MD³, \\ Robert L. Phillips, Jr., MD MSPH ${ }^{4}$, and Andrew Bazemore, MD MPH²
}

'Division of General Medicine and Geriatrics, Emory University School of Medicine, Atlanta, GA, USA; ${ }^{2}$ Robert Graham Center Policy Studies in Family Medicine \& Primary Care, Washington, DC, USA; ${ }^{3}$ Center for Primary Care, Global Health and Social Medicine Harvard Medical School, Boston, MA, USA; ${ }^{4}$ The American Board of Family Medicine, Washington DC, USA.

$\mathrm{J}$ Gen Intern Med 34(12):2708-10

DOI: $10.1007 / \mathrm{s} 11606-019-05338-3$

(c) Society of General Internal Medicine 2019

\section{INTRODUCTION}

Four essential features of primary care, identified by Barbara Starfield, include the following: first contact, continuity, coordination, and comprehensiveness. ${ }^{1}$ Comprehensiveness, defined as offering a "range of services broad enough to care for all health needs except those too uncommon to maintain competence," includes meeting the large majority of each patient's physical and mental healthcare needs. ${ }^{1}$ However, while comprehensiveness is thought to be in decline among primary care physicians (PCPs), little has been done to capture its value in policy-relevant terms such as cost and quality, important in this era of value-based purchasing. ${ }^{2}$ A recent study developed and tested a measure of comprehensiveness among family physicians revealed a modest association with lower healthcare utilization and costs among Medicare patients. $^{3}$ This paper extends this work by comparing family physicians and general internists in comprehensiveness and its impact on similar outcomes.

\section{METHODS}

We obtained all 2011 Part A and Part B Medicare claims for fee-for-service Medicare beneficiaries seen at least once by physicians in a nationally representative sample of PCPs drawn from the 2010 AMA Masterfile, using specialty codes to locate all GIM/FPs without second specialty. We excluded hospitalists (those with more than $80 \%$ of their E\&M claims delivered in the hospital setting). To link beneficiaries to a PCP, we identified the one who provided most of the E\&M

Received February 5, 2019

Revised August 6, 2019

Accepted August 27, 2019

Published online September 13, 2019 office services for each beneficiary. We used the BerensonEggers Typology of Service (BETOS) codes to construct a comprehensiveness measure by capturing the range of services performed by primary care physicians. ${ }^{3}$ We counted the total number of BETOS codes (excluding services infrequently provided by PCPs) that accounted for $90 \%$ of the physician's services. Our sample is further restricted to patients 65 years or older and to PCPs with 30 or more patients. We used Stata 14.2 to perform multi-level linear regression, controlling for patient- and physician-level characteristics (see note of Table 2).

\section{RESULTS}

From the 2011 Medicare data, we identified 1,107,709 beneficiaries cared for by 2682 general internists and 3396 family physicians. General internists and family physicians varied in their provision of services whether using all services or when restricted to the $90 \%$ most common services provided by a physician (Table 1). More general internists billed for hospitalbased codes $(p<0.001)$, while family physicians were more likely to provide care in emergency departments.

In our multivariate analyses, we found a substantial negative effect of comprehensiveness on charges and hospitalizations, with increasing comprehensiveness associated with fewer hospitalizations and lower costs for both internists and family physicians (Table 2). With respect to Part A and Part $\mathrm{B}$ allowed charges, our combined model indicates that the patients of general internists had spending that is about 7.4\% higher than the patients obtaining care from family physicians. Across specifications, there is about a $22-26 \%$ difference in overall spending between the patients obtaining most of their care from physicians in the lowest (BETOS score of 1) and highest (6-9) groups. There is no statistically significant difference across specialties $(p=0.48)$. Similarly, for hospitalizations, there is no specialty difference in the relation between hospitalizations and comprehensiveness $(p=0.608)$. 
Table 1 Percentage of Family Physicians and General Internists Providing Select BETOS Services, by Specialty and Selection Criteria

\begin{tabular}{|c|c|c|c|c|c|c|}
\hline & \multicolumn{3}{|l|}{ All services } & \multicolumn{3}{|c|}{$90 \%$ most commonly provided } \\
\hline & $\begin{array}{l}\text { Family } \\
\text { physicians }\end{array}$ & $\begin{array}{l}\text { General } \\
\text { internists }\end{array}$ & $\underset{\text { value }}{p}$ & $\begin{array}{l}\text { Family } \\
\text { physicians }\end{array}$ & $\begin{array}{l}\text { General } \\
\text { internists }\end{array}$ & value \\
\hline $\begin{array}{l}\text { Evaluation and management services } \\
\text { Office visits }\end{array}$ & 96.4 & 98.2 & \multirow{3}{*}{$\begin{array}{l}< \\
0.001 \\
< \\
0.001 \\
0.342\end{array}$} & 91.2 & 89.9 & 0.061 \\
\hline Hospital visit & 40.8 & 60.7 & & 21.0 & 34.1 & \multirow{3}{*}{$\begin{array}{l}< \\
0.001 \\
< \\
0.001 \\
0.177 \\
0.056 \\
< \\
0.001\end{array}$} \\
\hline Emergency room visit & 8.7 & 10.9 & & 2.8 & 1.5 & \\
\hline $\begin{array}{l}\text { Home visit } \\
\text { Nursing home visit } \\
\text { Specialist — other }\end{array}$ & $\begin{array}{l}14.1 \\
33.0 \\
81.3\end{array}$ & $\begin{array}{l}14.2 \\
36.3 \\
82.2\end{array}$ & $\begin{array}{l}0.591 \\
0.466 \\
0.126\end{array}$ & $\begin{array}{l}0.9 \\
11.5 \\
35.2\end{array}$ & $\begin{array}{l}1.2 \\
10.6 \\
27.3\end{array}$ & \\
\hline $\begin{array}{l}\text { Procedures } \\
\text { Ambulatory procedures-skin }\end{array}$ & 65.3 & 33.1 & \multirow{3}{*}{$\begin{array}{l}< \\
0.001 \\
< \\
0.001 \\
< \\
0.001\end{array}$} & 2.7 & 0.9 & \multirow{3}{*}{$\begin{array}{l}< \\
0.001 \\
< \\
0.001 \\
< \\
0.001\end{array}$} \\
\hline Minor procedures - musculoskeletal & 61.9 & 39.5 & & 1.4 & 0.4 & \\
\hline Minor procedures - other (Medicare fee schedule) & 93.8 & 86.7 & & 15.3 & 7.9 & \\
\hline $\begin{array}{l}\text { Tests } \\
\text { Lab tests-routine venipuncture (non-Medicare } \\
\text { fee schedule) }\end{array}$ & 62.6 & 57.1 & \multirow{5}{*}{$\begin{array}{l}< \\
0.001 \\
< \\
0.001 \\
< \\
0.001 \\
< \\
0.001 \\
0.286\end{array}$} & 40.7 & 35.5 & \multirow{3}{*}{$\begin{array}{l}< \\
0.001 \\
< \\
0.001 \\
0.679\end{array}$} \\
\hline Lab tests-blood counts & 37.0 & 28.2 & & 8.7 & 7.4 & \\
\hline Lab tests-glucose & 54.5 & 43.3 & & 3.7 & 4.0 & \\
\hline Lab tests - other (non-Medicare fee schedule) & 78.0 & 67.3 & & 38.3 & 32.6 & \multirow{3}{*}{$\begin{array}{l}< \\
0.001 \\
< \\
0.001 \\
0.031\end{array}$} \\
\hline Other tests - electrocardiograms & 86.9 & 84.9 & & 5.0 & 12.7 & \\
\hline Other tests - other & 75.4 & 69.0 & \multirow{3}{*}{$\begin{array}{l}\dot{<} 0.001 \\
< \\
0.001\end{array}$} & 4.5 & 5.6 & \\
\hline Summary BETOS score & 8.9 & 8.1 & & 2.8 & 2.7 & \multirow{2}{*}{$<$} \\
\hline Observations & 3598 & 2832 & & 3396 & 2682 & \\
\hline
\end{tabular}

Source: 2011 Medicare Claims Data (Part B)

Note: BETOS Berenson-Eggers Typology of Services. "All services" refers to the percentage of family physicians or general internists who provided the service at least once. "Services accounting for the $90 \%$ most commonly provided" refers to the percentage of services for each specialty after excluding the least common services provided by physicians. The summary BETOS score is the mean of the count of different types of services by a physician, across each specialty and selection criteria

Table 2 Association Between BETOS Comprehensiveness Measure and Part A and Part B Allowed Charges and Hospitalizations

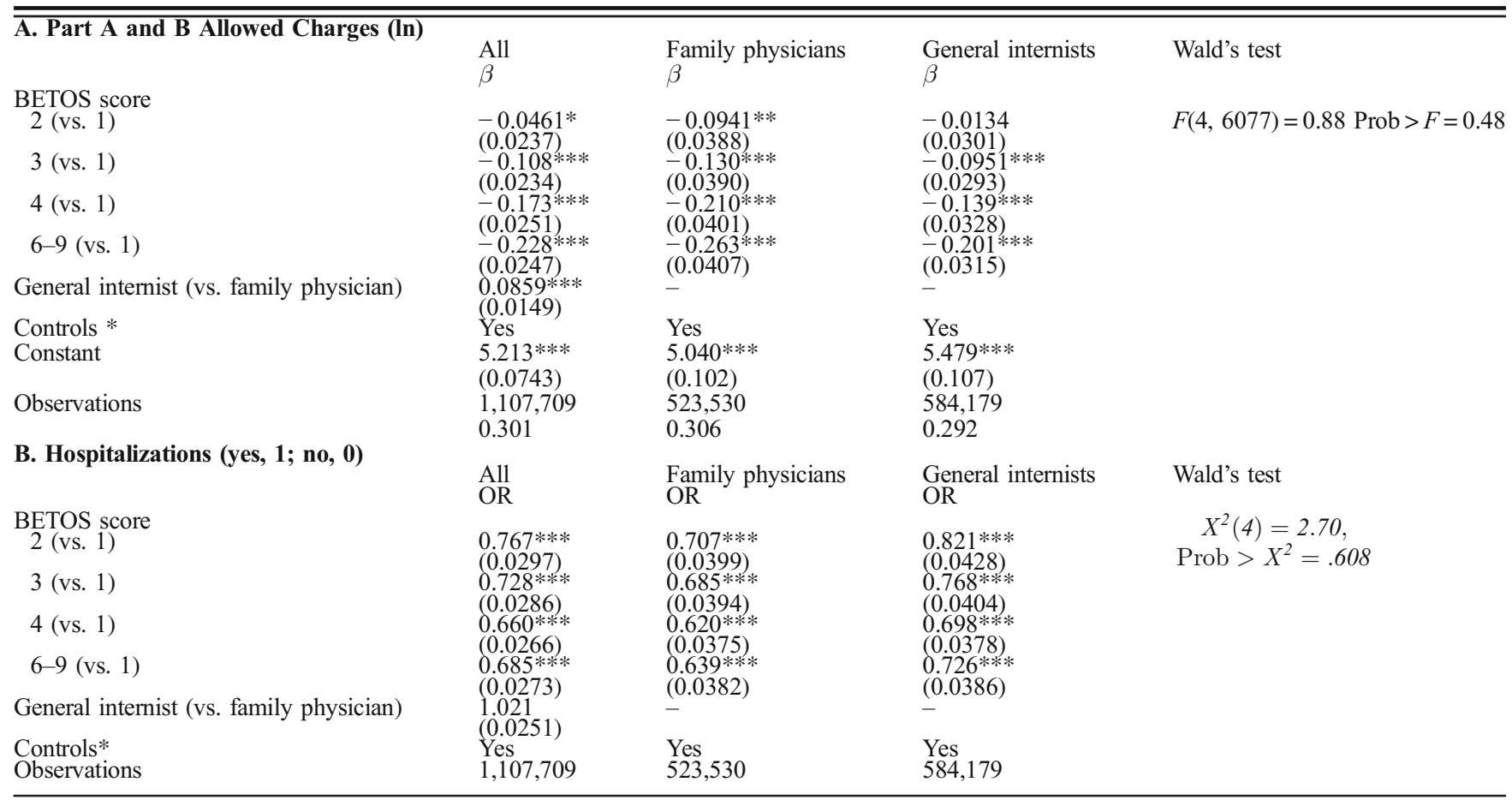

Source: 2011 Claims Data (Parts A and B). Note: BETOS Berenson-Eggers Typology of Services, FM family medicine, OR odds ratio. The unit of analysis is the beneficiary obtaining care from 3396 family physicians and 2682 general internists. Standard errors were adjusted to account for the clustering of patients by physician. A Wald test is a test that the four BETOS score coefficients are equal across specialty. *All models include controls for patient-level characteristics - age, gender, race/ethnicity, Charlson score, and number of primary care visits - and physician-level characteristics - gender, years since graduation, Medicare FFS patients, international medical school, rural location, and percent of care provided in hospital 


\section{DISCUSSION}

Despite differences in training and practice, general internists share with family physicians associations between increasing comprehensiveness and lower Medicare beneficiary costs highlighting the importance of comprehensiveness in primary care regardless of the type of primary care physician providing the care. The finding that general internists have patients with higher allowed charges is perhaps due to their concentration in higher spending areas. ${ }^{4}$ These findings further validate a novel use of claims and BETOS codes to generate and test a potential provider-level measure of practice patterns relevant to cost and quality in healthcare systems. ${ }^{1}$ This study has notable limitations, including its assessment of only a single year of claims and a Medicare population. Patient experience, an important facet of high-value care not captured in claims, was thereby not considered in our model. Additionally, alternative measures such as "new problem management" and "involvement in patient conditions" described by O'Malley and Rich could further capture comprehensiveness with more reliability. ${ }^{5} \mathrm{Fu}-$ ture research should use other source data and study additional populations, as well as focus on which specific BETOS codes are associated with lower healthcare costs, fewer hospitalizations, and other policy-relevant outcomes.

Corresponding Author: Tracey L. Henry, MD MPH MS; Division of General Medicine and Geriatrics, Emory University School of Medicine, Atlanta, GA, USA (e-mail: thenry@emory.edu).

\section{Compliance with Ethical Standards:}

The American Academy of Family Physicians Institutional Review Board approved this study without restrictions.

Conflict of Interest: The authors declare that they do not have a conflict of interest.

\section{REFERENCES}

1. Starfield B. Primary Care: Balancing Health Needs, Services, and Technology. New York: Oxford University Press, 1998.

2. O'Malley AS and Rich EC. Measuring Comprehensiveness of Primary Care: Challenges and Opportunities. J Gen Intern Med 2015; 30 (Suppl 3): 568-575.

3. Bazemore A, Petterson S, Peterson L, Phillips RL. More comprehensive care among Family Physicians is associated with lower costs and fewer hospitalizations. Ann Fam Med. 2015;13(3).

4. Phillips RL, Dodoo MS, Green LA, Fryer GE, Bazemore, AW, McCoy KI, Petterson SM. Usual Source of Care: An Important Source of Variation in Health Care Spending. Health Aff, 2009; 28 (2):567-77.

5. O'Malley AS, Rich EC, Shang $\mathbf{L}$, et al. New approaches to measuring the comprehensiveness of primary care physicians. Health Serv Res 2019;00:1-11.

Publisher's Note Springer Nature remains neutral with regard to jurisdictional claims in published maps and institutional affiliations. 